\title{
IR photo-acoustic sensors of different chemicals: review of practical realization
}

A. A. Karapuzikov ${ }^{a}$, A. I. Karapuzikov, ${ }^{\mathrm{a}, \mathrm{b}}$, D. B. Kolker, ${ }^{\mathrm{a}, \mathrm{b}, \mathrm{c}}$, M. K. Starikova ${ }^{\mathrm{a}, \mathrm{c}}$, I. V. Sherstov ${ }^{\mathrm{a}, \mathrm{b}}$, D. A. Kashtanov $^{\mathrm{a}, \mathrm{b}}$, F. A. Mayorov ${ }^{\mathrm{d}}$

a) Special technologies, Ltd., Zelenaya Gorka 1/3, Novosibirsk 620060, Russia

b) Institute of Laser Physics, Siberian Branch, Russian Academy of Sciences, pr. Akademika Lavrent'eva 13/3, Novosibirsk 630090, Russia

c) Novosibirsk State Technical University, pr. K. Marksa 20, Novosibirsk 630092, Russia

d) HLS Hypertech Laser Systems GmbH, Luebeck, Germany

In recent years the method of laser photoacoustic spectroscopy (LPAS) has become an important method for monitoring of gas chemical agent in atmosphere because of its simplicity experimental $r$ ealization, safety, high sensitivity (ppb- ppt level) [1-2]. LPAS makes to take measurements in real time with a minima 1 volume of gas sample or in continuous pumping mode of the analyzing gas sample. The LPAS detectors do not require using of expensive high-reflectivity mirrors as opposed to CRDS method. Capacities of LPAS sensors generally increase with increasing laser energy as far as acoustic signal are proportional to optical power absorbed in detector. This explains the increasing number of LPAS works with the advent of tunable quantum cascade mid-IR laser with a high average power [3-5].

In this presentation we will show few gas analyzers based on LPAS, which are designed in Special Technologies Ltd., with the participation of Institute of Laser Physi cs and V.E. Zuev Institute

of Atmospheric Optics Russian Academy of Sciences, Siberian Branch. Each device was developed for different technological and scientific tasks.

Our first gas analyzer is based on $\mathrm{CO}_{2}$-lasers with combined resonance photoacoustic detector [6]. The special feature our method of approach is possibility of developing a compact sealed waveguide $\mathrm{CO}_{2}$ lasers. The design and parameters of the la sers were optimized for achieve the best consumer properties while the price of the product are minimized. 


\section{Leak detector $\mathrm{SF}_{6}$}

The first production sample based on LPAS is $\mathrm{SF}_{6}$ LaserGasTest gas leak detector (figure 1). The leak detector meant for register concentration of $\mathrm{SF}_{6}$ in high-voltage gas insulated equipment [7].

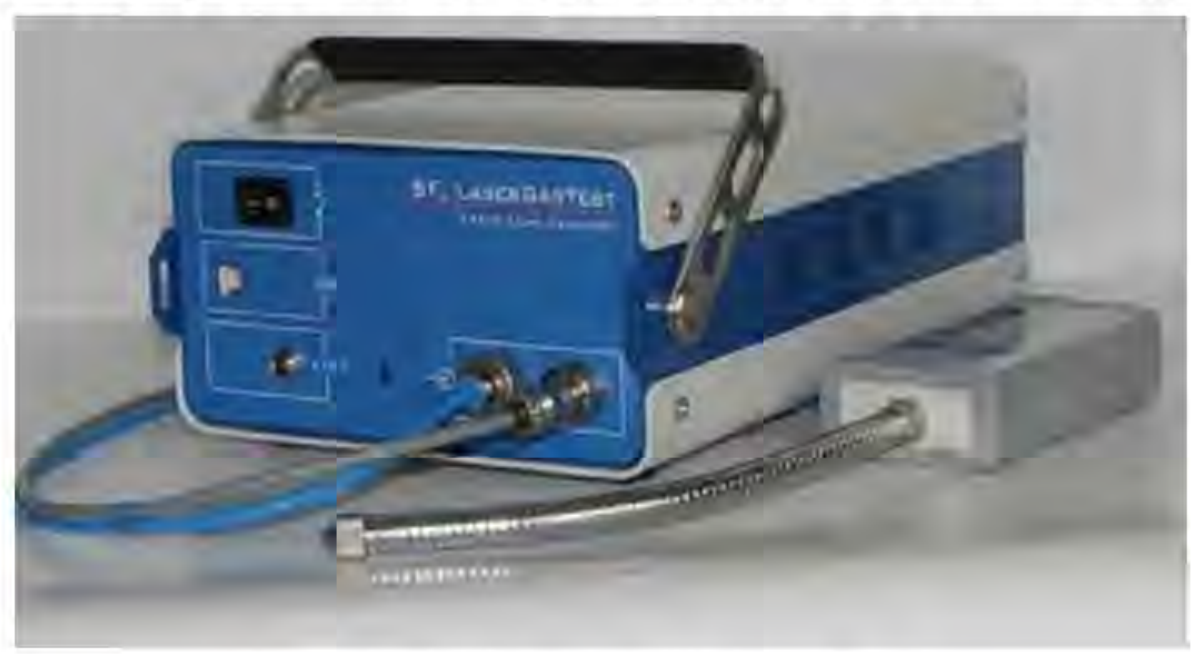

Figure 1 - Leak detector $\mathrm{SF}_{6}$ LaserGasTest

The $\mathrm{CO}_{2}$ lasers lines shows a strong overlap with the absorption band of $\mathrm{SH}_{6}$. So, to create an $\mathrm{SF}_{6}$ gas sensor, it is enough to use $\mathrm{CO}_{2}$ laser in free running.

The limit capacities are realized by using CW lasers with minimum line width by using amplitude modulation radiation using mechanical chopper. This mode does provide a minimum level of intrinsic laser amplitude noise and makes the minimum acoustic noise of the modulator. However, in this regime laser is consume high power, which limit the consume properties portable device based on it. For this reason, we decided to use a repetitively pulsed laser with a high radiation pulse ratio. In pulse- periodic mode the laser consumes essentially smaller power which does not exceed $10-15 \mathrm{~W}$. In additional, pulse-periodic laser is used forced pumping.

Due to the laser has higher output peak power and higher efficiency. It reduces requirements to quality of optical elements. The same factor significantly increases the laser lifetime in the sealed-off condition.

Nonetheless, the increasing of the amplitude fluctuation level of laser radiation from changing resonance frequency of the cavity due to thermal, acoustic and others processes is unavoidable negative effect by pulsed pumping of the active laser medium. For this reason in paper [8] on LPAS intro cavity spectroscopy for achievement of high sensitivity $\mathrm{CW}$ pump of the $\mathrm{CO}_{2}$ - laser has been used.

Blog diagram of LaserGasTest detector is presented on figure 2. The radiation from the periodical pulsed laser passing through PAD- 1, then passing through the reference bandwidth PAD-2 filled $\mathrm{SF}_{6}$ too. Analyzed atmospheric air is pumping through probe sensor by micropump. 


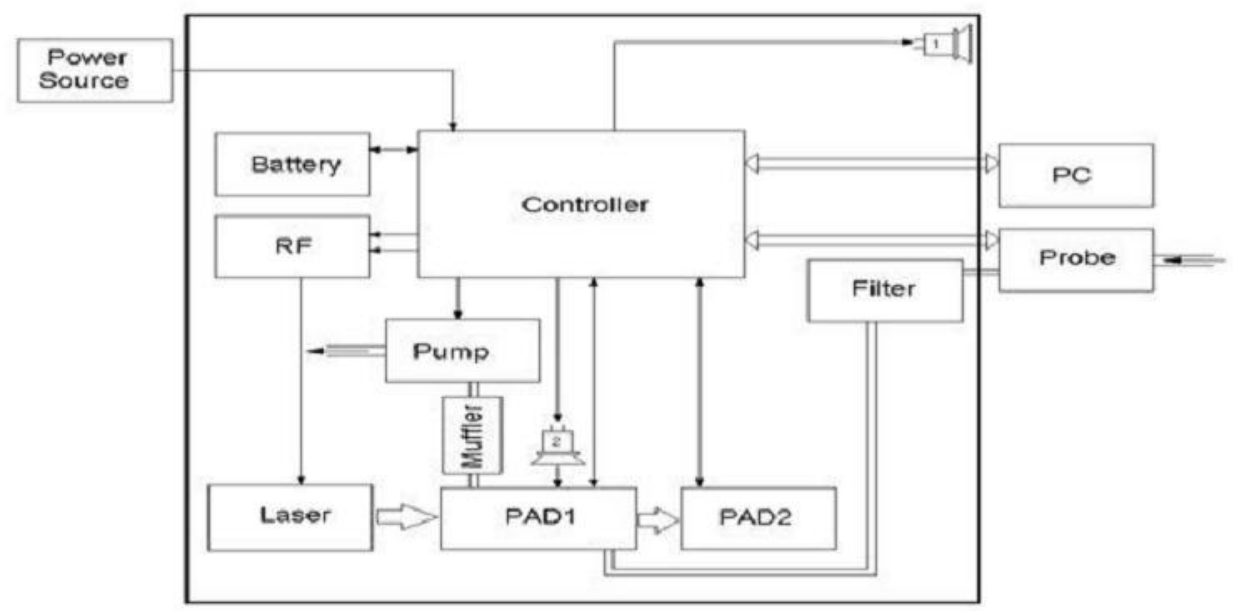

Figure 2 - Block diagram of $\mathrm{SF}_{6}$ LaserGasTest detector

The controller is managed of the lase $r$, resonance frequency of detector, measuring the signals from instrument and the reference cells. The controller is operating by probe laying speed and provides the relationship between gas analyzer and PC.

It appears, the real sensibility $1 \mathrm{ppb}$ of $\mathrm{SF}_{6} \mathrm{~L}$ aserGasTest detector is to be enough for practical implementation $[9,10]$. The application of compact periodically pulsed $\mathrm{CO}_{2}$ laser is allowed to reduce the dimension $\quad \mathrm{s}$ of device. Compact device was supplied by standard PC battery. The autonomic operation $\mathrm{t}$ ime of gas detector is 8 hours. The relative error of measurements of the insulating gas concentration, as shown in work [11], can be equal less than $1 \%$.

The technical specifications are presented in table 1.

Table 1

\begin{tabular}{|l|l|}
\hline \multicolumn{2}{|c|}{ Technical specifications } \\
\hline Detected gas & $\mathrm{SF}_{6}$ \\
\hline Sensitivity to $\mathrm{SF}_{6}:$ & \\
- Concentration & $0.01 \mathrm{ppm}$ \\
- Leak intensity & $0.02 \mathrm{~g} /$ year \\
\hline Type of detector & Photo-acoustic detector \\
\hline Probe laying speed (option) & $10 \mathrm{sm}^{3} / \mathrm{s}$ \\
\hline Response time delay & $2 \mathrm{~s}$ \\
\hline Start-up time & $0,5 \mathrm{~min}$ \\
\hline Indication & Digital, sound, graphic \\
\hline Power consumption: & \\
- Idle mode & $1 \mathrm{VA}$ \\
- Measuring mode & $15 \mathrm{VA}$ \\
- Charging mode & $50 \mathrm{VA}$ \\
\hline Continuous operation time & $6 \mathrm{hours}$ \\
\hline Dimensions & \\
- leak detector & $320 \times 190 \times 115 \mathrm{~mm}$ \\
- probe & $122 \times 60 \times 30 \mathrm{~mm}$ \\
- length of telescopic intake & $220-980 \mathrm{~mm}$ \\
- AC/DC adapter & $130 \times 50 \times 30 \mathrm{~mm}$ \\
- transportation case & $400 \times 250 \times 180 \mathrm{~mm}$ \\
\hline
\end{tabular}


The interesting application of $\mathrm{SF}_{6} \quad$ LaserGasTest gas leak detector is appearance measurement annual $\mathrm{SF}_{6}$ leak from gas-filled isolator. Application of $\mathrm{SF}_{6}$ LaserGasTest gas leak detector is permit to define leakage for period of several hours instead of several months. The isolator is put to special hermetic chamber (figure 3), in which has valve for mixing air with insulating gas. The concentration of $\mathrm{SF}_{6}$ was measured by the laser gas analyzer in the equal period time. The leakage rate is calculated by changing concentration of know interval of time.

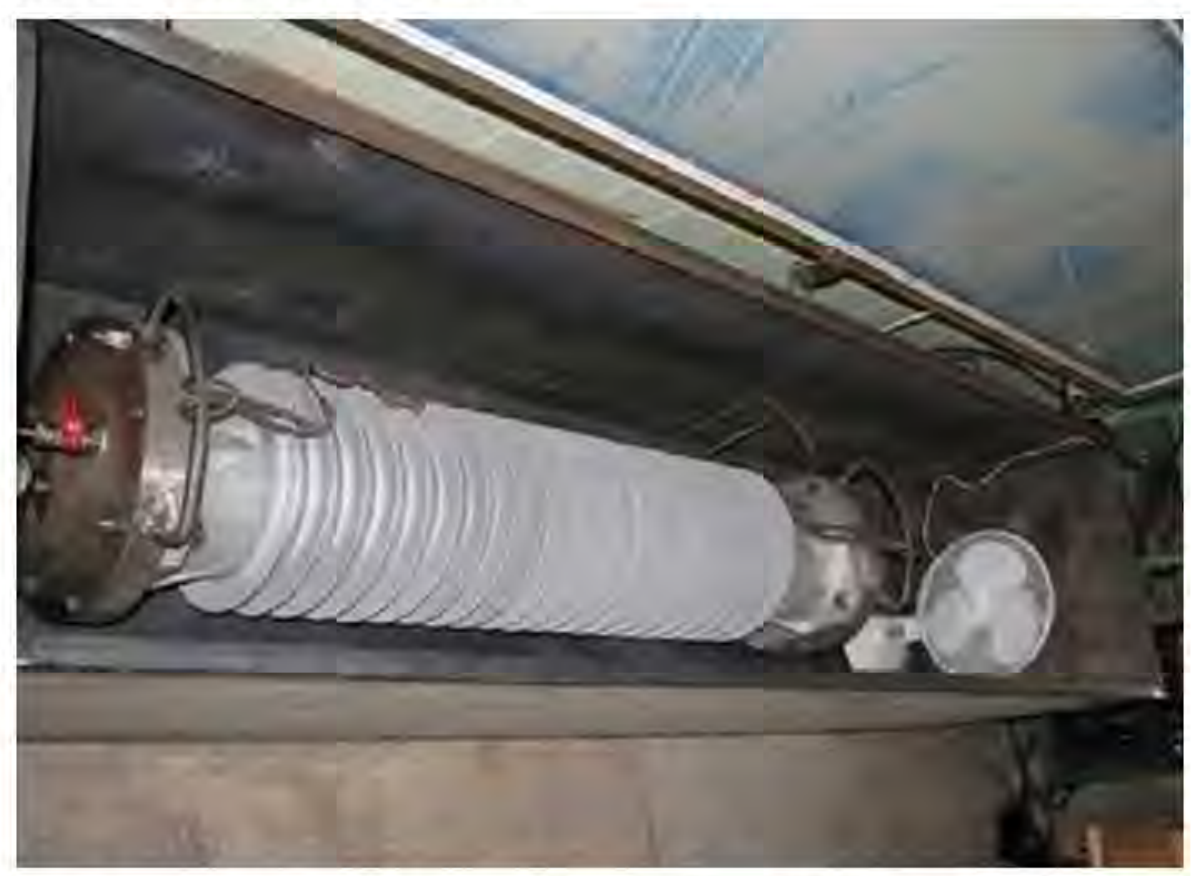

Figure 3 - Isolator testing, Novosibirsk 2008

$\mathrm{SF}_{6}$ LaserGasTest gas leak detector is purchased equipment to China, Japan, Russia and Korea. Now work is in progress for withdrawal of a gas detector on European market.

\section{Gas analyzer LGA-2}

The next step of developing gas analyzers is a model LGA- 2 based on the tunable waveguide periodically pulsed $\mathrm{CO}_{2}$ laser $[12,13]$. This system was initiated by medical researches for exhaled breath dia gnostic. The basement of gas analyzer is automatically tunable $\mathrm{CO}_{2}$ laser with air-cooled system.

In the figure 4 absorption spectra of $\mathrm{CO}_{2}$ in the gas mixing $\mathrm{CO}_{2}+\mathrm{N}_{2}$ (atmospheric pressure) is shown. The experimental data are corresponded of theoretical results from HITRAN-2004. 


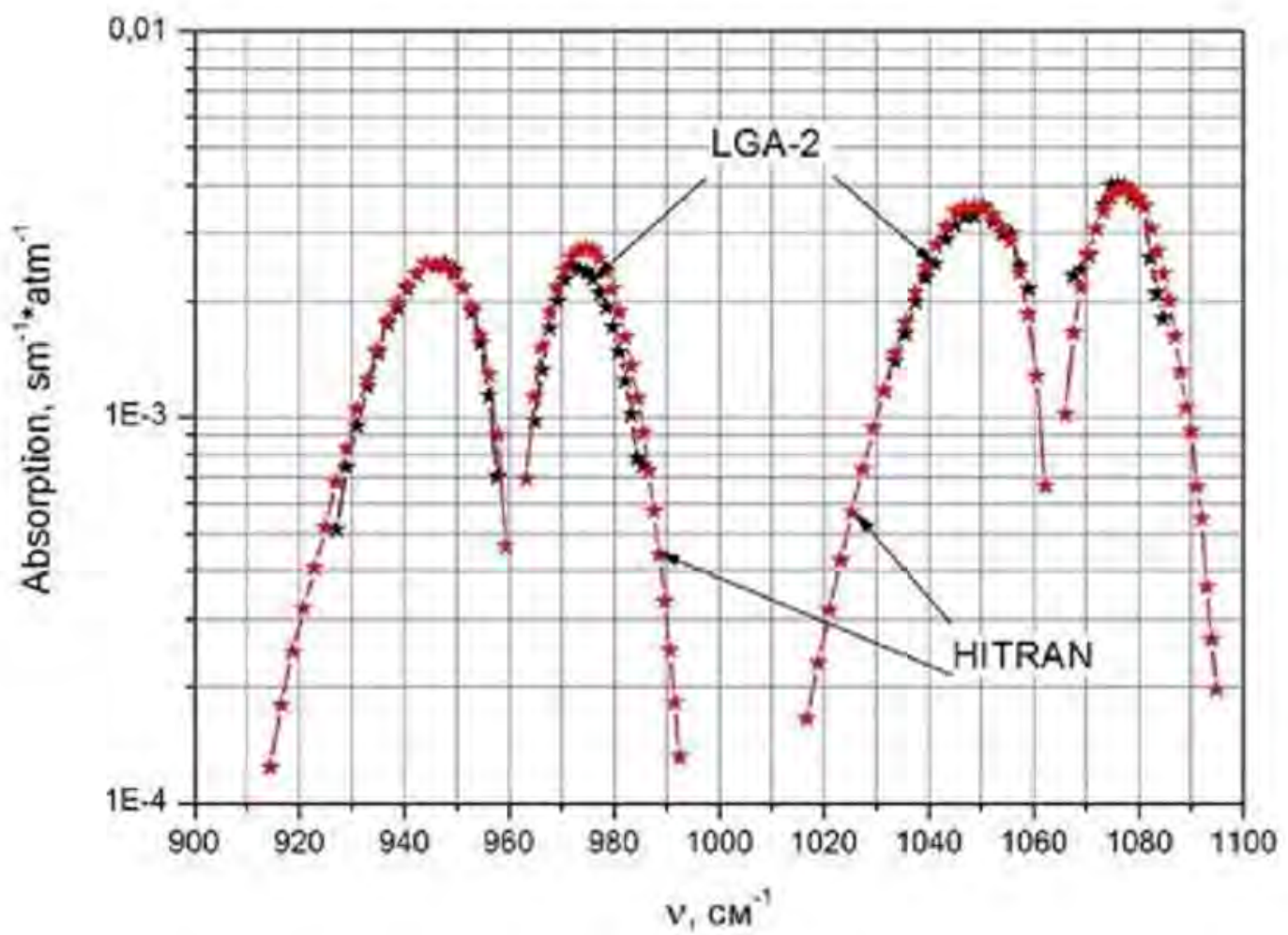

Figure 4 - Theoretical (HITRAN-2004) and experimental $\mathrm{CO}_{2}$ (LGA-2) absorption spectra

Gas analyzer LGA-2 is used for detection exhaled breath to a set of data on the correlation of changes in the concentration of gaseous markers from sick and healthy patients [14].

The narrow spectral range of $\mathrm{CO} 2$ laser was defined foe exhaled breath diagnostic, but this technique may be helpful for fast diagnostic and identification the wide number of famous toxic agent [15]. These gas sensors are p roduced commercial interest because of low cost and high efficiency for solving of different universal tasks.

The another problem is the detection of gas probes and identification in real time. Unfortunately, the time of recording spectra from 9.2-10.8 $\mu \mathrm{m}$ (tuning $\mathrm{CO}_{2}$ by 60 laser lines) is several minutes. This fact is dramatic because during this time the gas probe is changing.

For solving this problem, we are proposing the method of identification gas probe by testing a several wavelength and comparison s ignal relation with a database. To prove this method utilization of 5 organic solution are recorded. Two waveguides $\mathrm{CO}_{2}$ lasers at $9.55 \mu \mathrm{m}$ and $9.27 \mu \mathrm{m}$ and two PAD were applied. PAD signals are normalizing to reference signa ls from reference PAD for each channel to reduce the influence laser pump fluctuations. The air probe with evaporate organic solution pumped though both detectors in parallel.

The measurements were studied at $20^{\circ} \mathrm{C}$. The plug with liquid probe was brought to inlet flue gas path (or probe de tector was brought to inlet vessel with analyzing liquid) for registration analyzing 
probe response. The probe concentration is not controlled. The signal ratio on two wavelengths at the same measurement conditions is equal absorption cross-section $(m)$ ratio for testing probe:

$$
m=\frac{\sigma(9,55)}{\sigma(9,27)}
$$

The measurement results for 5 substances are presented in table 2 .

Table 2

\begin{tabular}{|c|l|c|c|}
\hline & \multicolumn{1}{|c|}{ Analyzing substances } & $\begin{array}{c}\text { Signal amplitude at 9.27 } \\
\mu \mathrm{m}(\text { a.u. })\end{array}$ & $m$ volume \\
\hline 1. & Vapor of ethanol $\left(\mathrm{C}_{2} \mathrm{H}_{5} \mathrm{OH}\right)$ & 300 & 0,39 \\
\hline 2. & $\begin{array}{l}\text { Vapor of isopropyl alcohol } \\
\left(\mathrm{C}_{3} \mathrm{H}_{8} \mathrm{O}\right)\end{array}$ & 6 & 0,31 \\
\hline 3. & Vapor of toluene $\left(\mathrm{C}_{6} \mathrm{H}_{8}\right)$ & 11 & 0,36 \\
\hline 4. & Vapor of acetone $\left(\mathrm{CH}_{3} \mathrm{CO}-\mathrm{CH}_{3}\right)$ & 6 & 0,34 \\
\hline 5. & $\begin{array}{l}\text { Vapor of } 1,2 \text {-dichloroethane } \\
\left(\mathrm{Cl}-\mathrm{CH}_{2}-\mathrm{CH}_{2}-\mathrm{Cl}\right)\end{array}$ & 2 & 1,43 \\
\hline
\end{tabular}

The signal amplitude at $9.27 \mu \mathrm{m}$ is characterized the probe absorption coefficient in condition of measurement. The volume of ratio is characterized type of substance. The dispersion of the volume of $m$ depends on many factors, and did not exceed $+/-5 \%$.

Goal of these experiments was demonstrated the possibility to vapor identification different subst ance. The multiwave $\mathrm{CO} 2$ registration is allow to identify a number of organic components. Even

utilization only two laser lines without tunability is open possibility precisely identifies 5 organic solutions. To increase determination accuracy $(\sim 100 \%)$ of $g$ as test is possible by applying of 4 lines. It is possible to employ systems of two lasers, one of them is tunable, but response time is decreasing.

For majority toxic agent $\mathrm{s}$ the strongest lines of molecular absorption leads at the region 9.2$11.5 \mu \mathrm{m}$ [8]. This spectral window is the correlated with a tuning range of the $\mathrm{CO}_{2}$ laser (base isotope and ${ }^{13} \mathrm{CO}_{2}$ isotope). Utilization of few fixed lines of $\mathrm{CO}_{2}$ lasers is allow detecting and indentified precisely general toxic agent in the air.

\section{LPAS gas analyzer with a tunable optical parametric oscillator}

The optical parametric oscillator (OPO) has broad wavelength coverage therefore we are researching new devices based on OPO for range extension LPAS sensors. This technique will allow covering wide spectral range from 2 to $12 \mu \mathrm{m}$ as compared with another laser sources and, particularly, quantum cascade lasers (QCL). But for so broad tunability are required up to 10 lasers used simultaneously. This makes device unique by complexity and price. 
The tuning range of nanos econd OPO based on P PLN crystal pumped Nd:YAG laser is 2-4.7 $\mu \mathrm{m}$ (idler wave). Expansion the spectral rang up to $11 \mu \mathrm{m}$ is possible by using nonlinear chalcogenide bulk crystal: $\mathrm{LiGaSe}_{2}$, $\mathrm{LiInSe}_{2}, \mathrm{AgGaS}_{2}$, and AgGaSe 2 [16-18].

We developed and researched an OPO experimental setup combined with photoacoustic detector. The pump laser was a Q- switched Nd:YAG (or Nd:YLF) laser operating at $1.064 \mu \mathrm{m}$ (or $1.053 \mu \mathrm{m}$, respectively).

The experimental setup consists of pump laser and two OPO: PPLN OPO (2-4.7 $\mu \mathrm{m})$ and AGS - OPO based on 3 bulk-crystals in the same cavity. The p hotoacoustic detector is used for the registration of absorption spectra testing gas probes.

The monolithic OPO cavities (figure 5 ) consist of two high- reflectivity mirrors at the signal wave. The out put mirror is transparent at the pump and idler wavelengths; the input mirror has a high transmission coefficient at the pump wavelength. The designed monolithic block allows to correct the cavity length by means of changing a distance between of two cylin dric holders in the flanges. The monolithic block design allows to vary the cavity configuration (confocal, spherical, Fabry-Perot, and half-spheric).

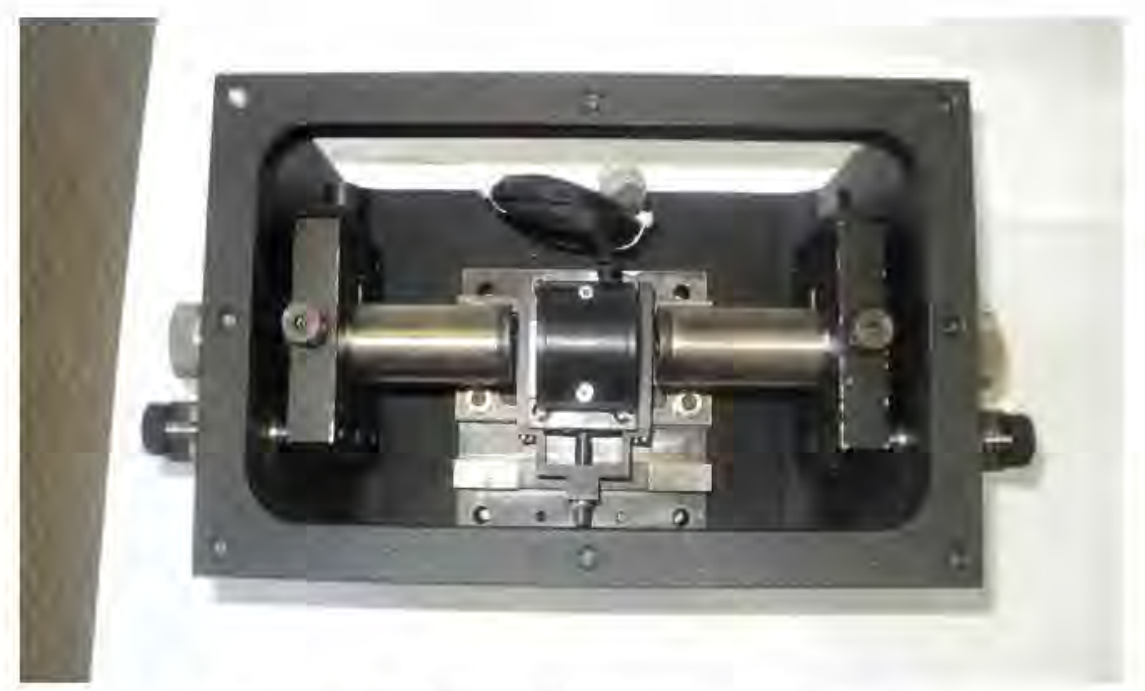

Figure 5 - The OPO monolithic cavity

OPO based on MgO:PPLN

A bsorption spectra of $\mathrm{H}_{2} \mathrm{O}$ (in range $2.7 \mu \mathrm{m}$ ), $\mathrm{C}_{2} \mathrm{H}_{4}(3.1-3.4 \mu \mathrm{m}$ ) and isotopic relationship ${ }^{13} \mathrm{CO}_{2} /{ }^{12} \mathrm{CO}_{2}$ (compared with theoretical) are investigated by using a tandem OPO-PAD. Below this absorption spectra are presented. 


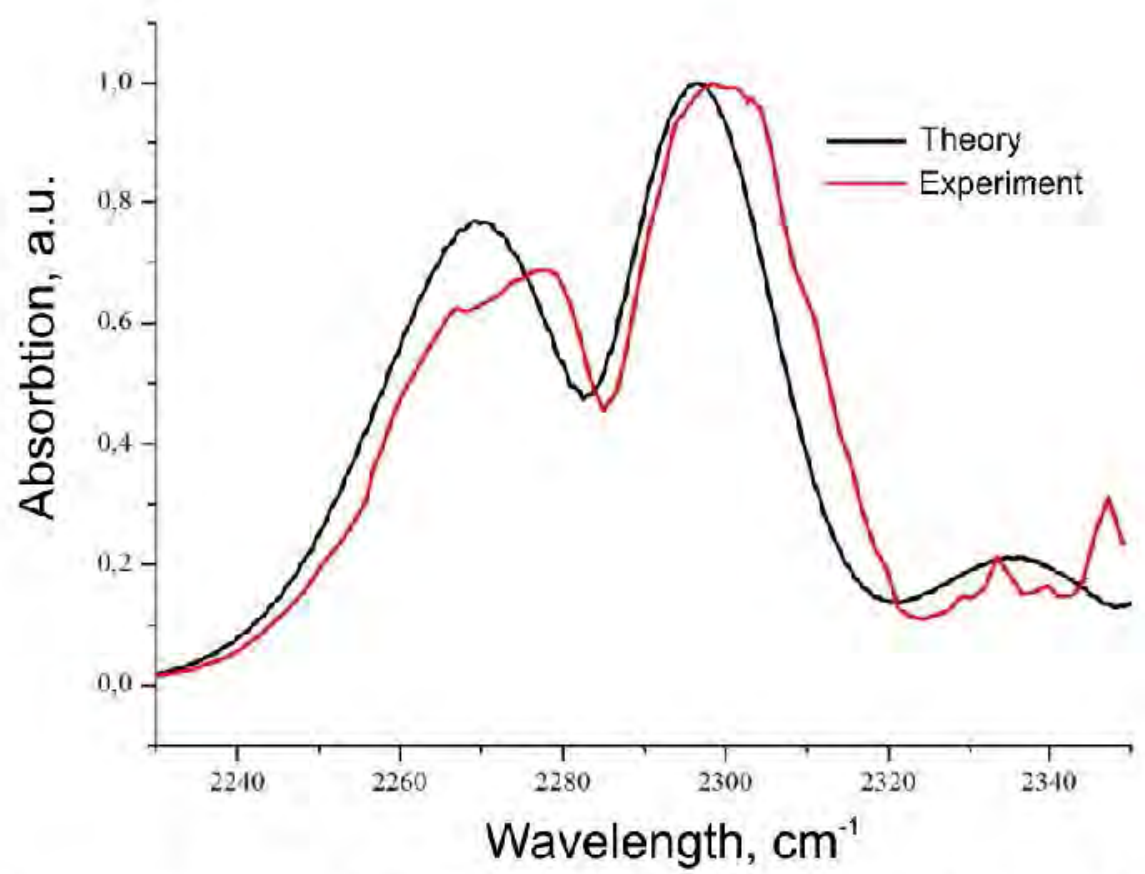

Figure 6 - Absorption spectra of $300 \mathrm{ppm} \mathrm{C}^{12} \mathrm{O}_{2}+1200 \mathrm{ppm} \mathrm{C}^{13} \mathrm{O}_{2}+\mathrm{Air}$ (HITRAN) compared with experimental result
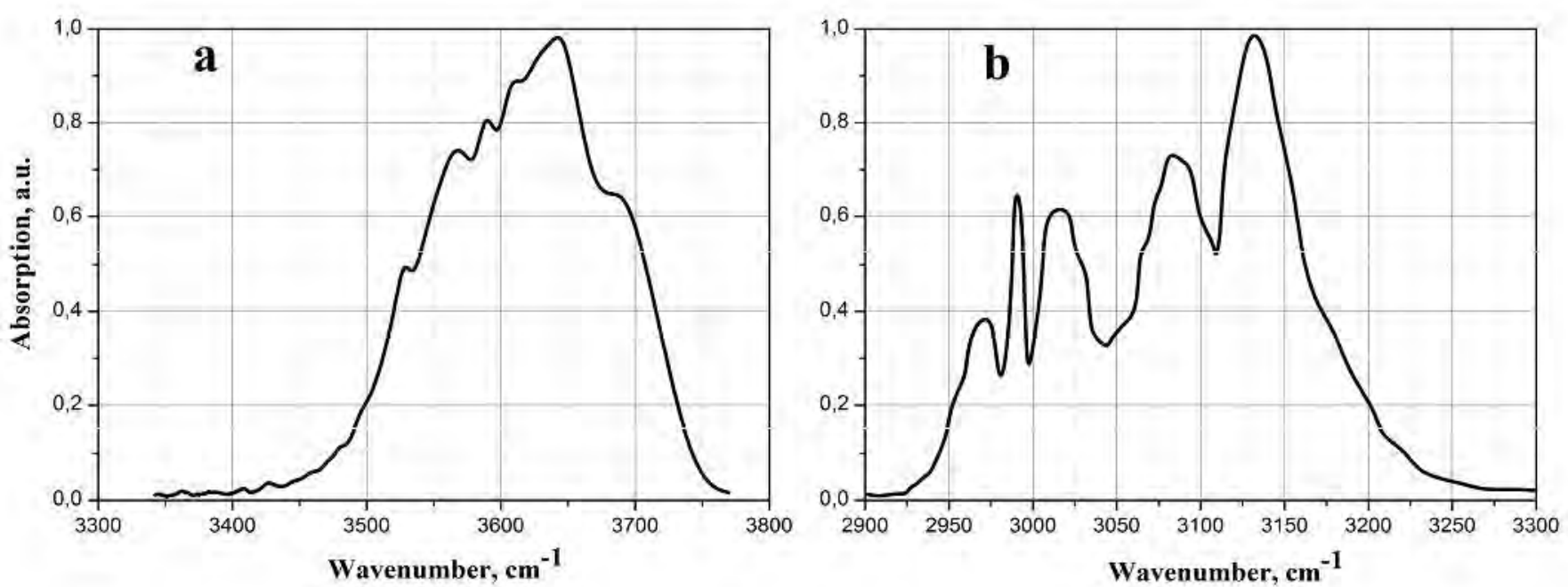

Figure 7 - The water $\mathrm{H}_{2} \mathrm{O}$ (a) and ethylene $\mathrm{C}_{2} \mathrm{H}_{4}$ (b) absorption spectra

\section{OPO based on bulk-crystals}

The use of chalcogenide crystals as a nonlinear medium OPO allowed the range up to $4 \mu \mathrm{m}$ to be overlapped. The advantages of these crystals are their relatively high thermal conductivity, large bandgap and, as a result, low two- photon absorption and a weak mismatch between the group velocities [17]. This OPO model is present on the figure below (figure 9). 


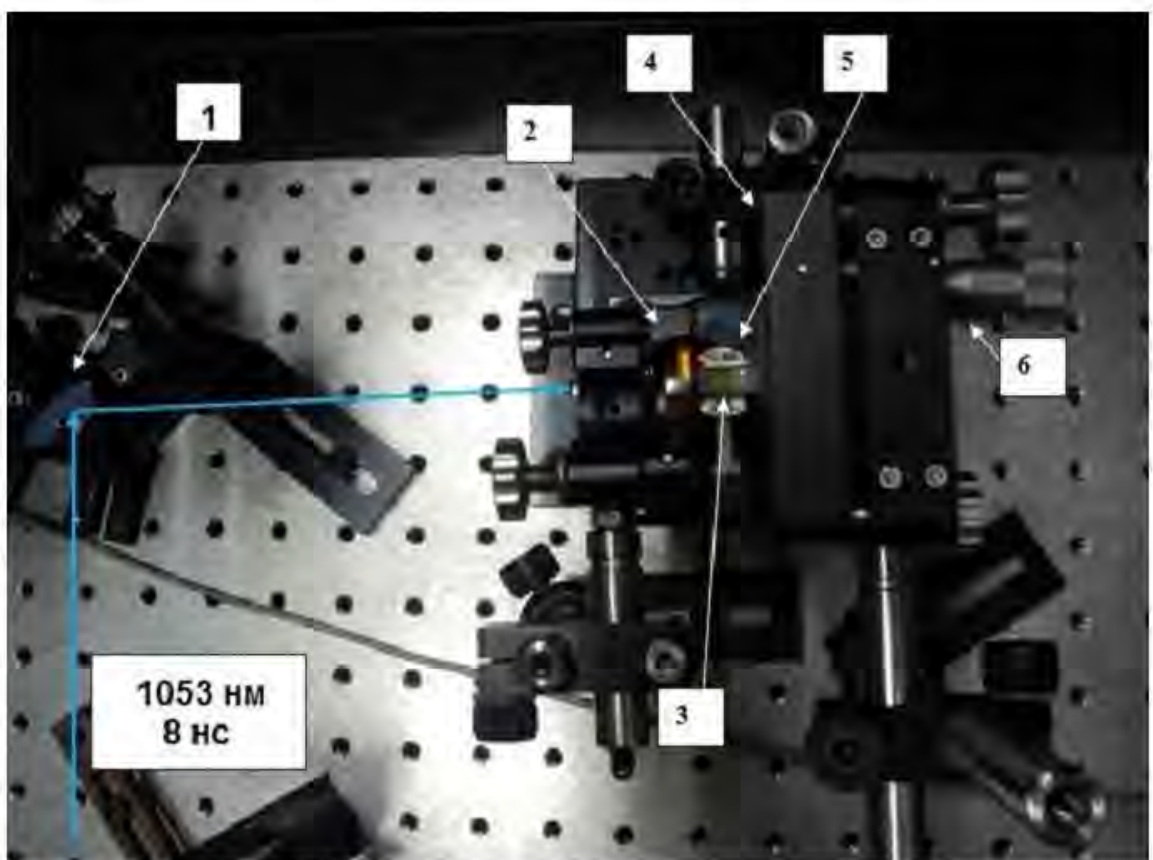

Figure 8 - OPO model based on bulk-crystals

1 - dichroic mirror; 2 - output dielectric mirror; 3 - nonlinear crystal; 4 -mirror; 5 - holder of nonlinear crystal; 6 - adjusting head of back mirror

Optical parametric oscillator based on chalcogenide crystals is allowed to cover wide tuning range from 4 to $10 \mu \mathrm{m}$.

The advantages of OPO combined with photoacoustic detector are:

- Wide spectral range;

- The OPO power in several times higher than diode laser power;

- The response linearity of the device for the variation of measured concentrations of 6 orders of magnitude;

- Simplicity in get results in real time more simply.

\section{Non-laser detector on PAS}

One more direction our researching is developing a non- laser detector based on PAS. The detection of gaseous impurities with absorption lines in a wide spectral range is possible, but non-laser gas sensors possess lower threshold sensitivity due to the large width of the spectral filter. Nevertheless, a number of companies are developing similar technology applied to solving specific probl ems, for example, the measurement of the isotopic ratio ${ }^{13} \mathrm{CO}_{2} /{ }^{12} \mathrm{CO}_{2}$ diagnosis or gas vapor composition of transformer oil et al.

We are developing the similar device for carrying out of the breath test. Mathematical modelling is spent and the technical decision for definition isotope relations ${ }^{13} \mathrm{CO}_{2} /{ }^{12} \mathrm{CO}_{2}$ in exhaled air is offered at carrying out of the breath test in a spectral range 4,0-4,5 microns. Our approach protected 
by the patent of the Russian Federation [19], is based on application of modern methods of the spectral modulation having a number of advantages before traditional amplitude modulation. Possibility of use tunable Fabry-Perot interferometer of the first order and a periodic inclination of the narrow-band spectral filter is considered.

\section{References}

1. Photoacoustic Spectroscopy in Trace Gas Monitoring Frans J.M. Harren, Gina Cotti, Jos Oomens, and Sacco te Lintel Hekkert in Encyclopedia of Analytical Chemistry R.A. Meyers (Ed.) pp. 22032226 Y John Wiley \& Sons Ltd, Chichester, 2000

2. Miklos A, Hess P, Bozoki Z (2001) Application of acoustic resonators in photoacoustic trace gas analysis and metrology Rev Sci Instrum, 72 (2001) pp. 1937-1955

3. A. Lyakh., R. Maulini, A. Tsekoun, R. Go, C. PflË ugl, L. Diehl, Q. J. Wang, F. Capasso, and C.

Kumar N. Patel, "3 W continuous- wave room- temperature single- facet emission from quantum cascade lasers based on non-resonant extraction design approach,” Appl. Phys. Lett. 95, 141113, 2009.

4. Anadi Mukherjee , Manu Prasanna, Michael Lane, Rowel Go, Ilya Dunayevskiy, Alexei Tsekoun, and C. Kumar N. Patel Optically multiplexed multi- gas detection using quantum cascade laser photoacoustic spectroscopy Applied Optics Vol. 47, Iss. 27, pp. 48844887 (2008)

5. Micha el E. Webber, Michael Pushkarsky, and C. Kumar N. Patel Optical detection of chemical warfare agents and toxic industrial chemicals: Simulation J. Appl. Phys. 97, 113101 (2005)

6. Chang- Myung Lee, Konstantin V. Bychkov, Venedict A. Kapitanov, Alexander I. Karapuzikov, Yurii N. Ponomarev, Igor V. Sherstov, and Vadim A. Vasiliev "High-Sensitivity Laser Photoacoustic Leak Detector", Opt. Eng. Vol. 46, 064302, 2007.

7. Vasil'ev V.A., Karapuzikov A.I., Karapuzikov A.A., Sherstov I.V. Laser photo- acoustic gas analyzer // Patent RF № 90905, 2009.10.21, Holder of patent - Special technologies Ltd.

8. F.G.M. Harren, F.G.C. Bijnen, J. Reuss, L.A.C.J. Voesenek, C.W.P.M. Blom. "Sensitive intracavity photoacoustic measurement with a $\mathrm{CO}_{2}$ waveguide laser", Appl. Phys., 1990, Vol. B50, pp.137-144.

9. Dolin A.P., Karapuzikov A.I., Koval'kova Yu. A. The efficiency of using laser leak detector "KARAT" for detection place and level defect formation, Electro, No. 6, 2009, P. 25-28

10. Sherstov I.V., Karapuzikov A.I., Vasiljev V.A., Zenov K.G. "Re search of metrological parameters of $\mathrm{SF}_{6}$ laser photo- acoustic detector" / In: XV International Symposium "Atmospheric and Ocean

Optics. Atmospheric Physics” (Krasnoyarsk, June 22- 28, 2008). Abstracts. - Tomsk: Institute of Atmospheric Optics SB RAS, 2008. - 200 pp. (Oral report, CO-20, p.108).

11. Kashtanov D.A., Vasil'ev V.A., Karapuzikov A.I., Sherstov I.V. The stabilization emission line of waveguide CO2 laser for laser photo- acoustic detector SF6 // Atmospheric and Oceanic Optics, V. 24, 2011, No. 6, P. 411-424 
12. Sherstov I.V., Karapuzikov A.I., Ageev B.G., Kapitanov V.A., Ponomarev Yu.N. "Photo-acoustic sensors and gas analyzers based on intellectual wave-guide $\mathrm{CO}_{2}$ - laser and their applications" / In: IX Russian- Chinese Symposium on Laser Physics and L aser Technology. Tomsk State University, Tomsk, October 26-31, 2008. (Oral report).

13. Vasil'ev V.A., Zenov K.G., Karapuzikov A.I., Sherstov I.V. Photo- acoustic laser gas analyzer based on tunable waveguide $\mathrm{CO}_{2} \quad$ laser // In: XVII International symposium on Atmospheric and Oceanic Optics, Tomsk, June 28 - July 01, 2011 (Oral report).

14. Ageev B.G., Kistinev Yu.V., Nikiforova O.Yu., Nikotina G.S., Fokin V.A. The use of an integrated assessment of the facility for the analysis of exhaled air and diagnosis of human diseases // Atmospheric and Oceanic Optics, 2010, Vol. 23, No. 7, P 570-579 (in Russian)

15 . C. K.N. Patel Laser photoacoustic spectroscopy helps fight terrorism: High sensitivity detection of chemical Warfare Agent and explosives Photoacoustic an d Photothermal Phenomena Journal The European Physical Journal - Special Topics Volume 153, Number 1 / January, 2008

16. Marchev G., Tyazhev A., Vedenyapin V., Kolker D., Yelisseyev A. Nd:YAG pumped nanosecond optical parametric oscillator based on $\mathrm{LiInSe}_{2}$ with tunability extending from 4.7 to $8.7 \mu \mathrm{m} / / \mathrm{Optics}$ Express, 2009, Vol. 17, Issue 16, P. 13441-13446.

17. Petrov V., Zondy J.-J., Bidault O., Isaenko L., Vedenyapin V., Yelisseyev A., Chen W., Tyazhev A., Lobanov S., Marchev G., Kolker D. , Optical, thermal, electrical, damage, and phase-matching properties of lithium selenoindate //JOSA B, 2010, Vol. 27, Issue 9, P. 1902-1927.

18. Kolker D.B., Pustovalova R.V., Starikova M.K., Karapuzikov A.I., Karapuzikov A.A., Kuznetsov O.M., Kistenev Yu. V. Optical parametric oscillator within 2.4- $4.3 \mathrm{mkm}$ pumped with a nanosecond Nd:YAG laser, , Atmospheric and Oceanic Optics, 2012, Vol. 25, No. 1, pp. 77-81 (in Russian)

19. Karapuzikov A.I., Karapuzikov A.A., Kashtanov D.A., Starikova M.K., Kistenev Yu.V. Photoacoustic gas analyzer // A pplication for a patent RF № 201147362, 2011.11.21, H older of patent Special technologies Ltd. 